\title{
A Comparative Analysis of Educator's and Peers' Influence on Students' Attitude to Mobile Social Media in Distance Learning
}

\author{
Andreas Ahrens \\ Hochschule Wismar
}

\author{
Jeḷena Zaščerinska \\ Centre for Education and Innovation Research
}

\begin{abstract}
Mobile social media is widely employed in higher education to provide students with an opportunity to learn regardless of time and place in order to obtain a higher education degree. However, little attention has been paid to the study of educator's and peers' influence on students' attitude to mobile social media in distance learning. The aim of the paper is to analyse educator's and peers' influence on students' attitude to mobile social media in distance learning underpinning elaboration of a hypothesis. The meaning of the key concepts of distance learning, blended learning, blended educational process and attitude is studied. Moreover, the study demonstrates how the key concepts are related to the idea of mobile social media and shows how the steps of the process are related: educator's and peers' influence on students' attitude to mobile social media $\rightarrow$ empirical study within a multicultural environment $\rightarrow$ conclusions. The results of the present research show that engineering students' positive attitude to mobile social media prevails. Directions of further research are proposed.
\end{abstract}

\section{Introduction}

Many universities throughout the world have already adopted or are planning to adopt mobile social media in many of their courses as a better way to connect students with the subjects they are studying [8]. Particularly, mobile social media in distance learning of higher education have already become an indispensable tool in both university staff and students' daily life. Mobile social media is widely employed in distance learning of higher education to provide students with an opportunity to learn regardless of time and place in order to obtain a higher education degree. In distance learning mobile social media allows students to access content anywhere/anytime to immerse himself/herself into that content (alone or interacting with educators or colleagues via web communication forms) and to interact with that content in ways that were not previously possible (via touch and voice recognition technologies, for instance) [8]. Hence, mobile social media and distance learning are closely inter-related.
Enhancement of education experience via mobile social media game has been analysed [16]. However, students' attitude to mobile social media in distance learning plays a two-fold role in distance learning within higher education:

- on the one hand, students' attitude to mobile social media influences students' distance learning, and,

- on the other hand, students' attitude to distance learning shapes students' application of mobile social media.

Thus, application of mobile social media in distance learning is driven by students' attitude to mobile social media in distance learning.

Against this background, little attention has been paid to the study of educator's and peers' influence on students' attitude to mobile social media in distance learning within higher education.

The aim of the paper is to analyse educator's and peers' influence on students' attitude to mobile social media in distance learning within higher education via a comparative study underpinning elaboration of a hypothesis. The meaning of the key concepts of distance learning, blended learning, blended educational process and attitude is studied. Moreover, the study demonstrates how the key concepts are related to the idea of mobile social media and shows how the steps of the process are related: educator's and peers' influence on students' attitude to mobile social media in distance learning within higher education $\rightarrow$ empirical study within a multicultural environment $\rightarrow$ conclusions.

The methodological background of the present contribution is based on the System-Constructivist Theory introduced as the New or Social Constructivism Pedagogical Theory. The SystemConstructivist Theory and, consequently, the System-Constructivist Approach to learning emphasize that human being's point of view depends on the subjective aspect as experience plays the central role in the knowledge construction process. Therein, the subjective aspect of human being's point of view is applicable to the present research.

The methodological background of the present contribution, namely the System-Constructivist Theory, contributes to the application of the methodological approach of the present research identified as the outcome based approach. The 
outcome-based approach is opposed to input-based approach. The outcome-based approach is resultoriented such as students' competence enrichment. In comparison, input-based approach is focused on the process. Application of the methodological approach, namely the outcome based approach, to the present research determines students' attitude to be an outcome of application of mobile social media in distance learning within higher education.

The novel contribution of this paper is the key participants of the blended educational process, namely educators and peers, who influence students' attitude to mobile social media in distance learning within higher education.

The remaining part of this paper is organized as follows: the next section introduces theoretical framework on educator's and peers' influence on students' attitude to mobile social media in distance learning within higher education. The associated results of an empirical study will be presented in the following section. Finally, some concluding remarks are provided followed by a short outlook on interesting topics for further work.

\section{Theoretical Framework}

The present part of the contribution demonstrates the definitions of attitude, mobile social media, distance learning within higher education.

As the methodological approach, namely the outcome based approach, to the present research is result-oriented, students' attitude as an outcome of application of mobile social media in distance learning within higher education has to be identified.

Students' attitude is part of competence as competence includes knowledge, skills and attitudes as depicted in Figure 1.

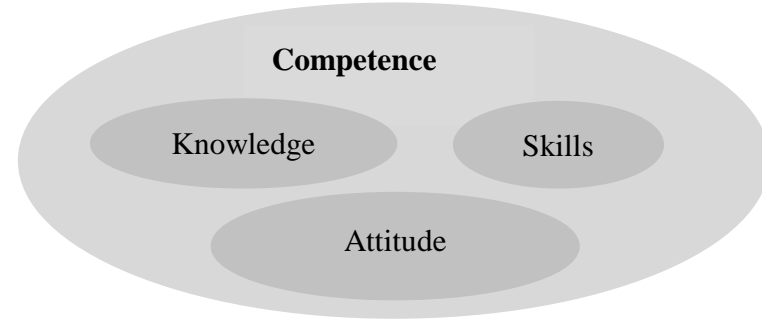

Figure 1. Elements of competence

These elements of competence, namely knowledge, skills and attitude, are inter-related. Students' negative attitude fails to promote the increase in the level of students' knowledge and skills as well as competence, in general. In contrast, students' positive attitude ensures the enrichment of the level of students' knowledge and skills as well as competence, in general.

Application of mobile social media in distance learning within higher education contributes to the enrichment of students' digital competence. Students' digital competences is of great importance as it serves as

- one of eight key competences for lifelong learning,

- a condition,

- factor and

- evaluation criterion of application of mobile social media in distance learning.

Hence, students' attitude serves not only as an outcome but also as a criterion of application of mobile social media in distance learning within higher education. It should be noted that criteria serve to structure, assess and evaluate while indicators determine developmental dynamics [18] and constructs differentiate a variable which is not directly observable. Criteria, indicators and constructs are identified via analysis of definition of the research object, structure of the research object and factors [18].

Understanding students' attitudes towards mobile social media in distance learning can help to determine the extent to which students utilize mobile social media in distance learning. Attitude has been defined by a number of researchers. Palmer and Holt define attitude as an individual's positive or negative feelings about performing the target behavior [15]. This implies that learners' positive or negative feelings about their use of mobile social media in distance learning would directly influence their behavior to use mobile social media in distance learning. Another definition is attitude identified as a combination of evaluative judgements about a phenomenon [5]. Analysis of these definitions of attitude and complementing the attitude definition formulated by Crites, Fabrigar, Petty [5] with the word individual leads to such a newly determined definition of attitude as an individual combination of evaluative judgements about a phenomenon. As well as, in comparison to attitude's positive or negative feelings determined by Palmer and Holt [15], attitude is differentiated into positive, neutral or negative as shown in Figure 2.

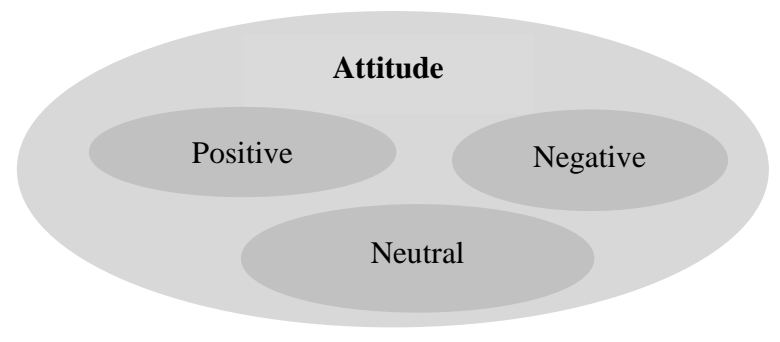

Figure 2. Attitude differentiation

Attitude differentiation is considered as levels of attitude shown in Table 1.

Table 1: Attitude as a criterion and levels of attitude 


\begin{tabular}{|c|c|c|c|}
\hline Criterion & \multicolumn{3}{|c|}{ Levels } \\
\cline { 2 - 4 } & Level 1 & Level 2 & Level 3 \\
\cline { 2 - 4 } & low & optimal & high \\
\cline { 2 - 4 } & $\mathbf{1}$ & 2 & 3 \\
\hline Attitude & Negative & Neutral & Positive \\
\hline
\end{tabular}

The nature of attitude is rooted in emotions. Thus, emotions and attitude are inter-related as demonstrated in Figure 3.

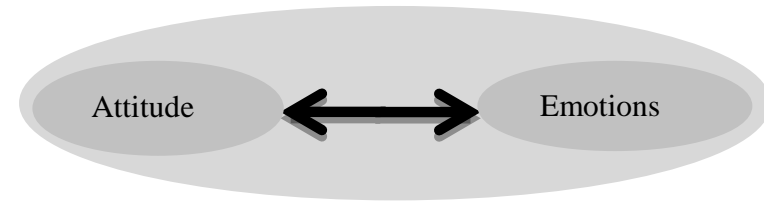

Figure 3: The relationship between attitude and emotions

However, emotions refer to psychology, and attitude - to pedagogy. Therein, psychological processes provide the basis for pedagogical developments.

Emotions are defined as nerve impulses. Emotions ensure this faster reaction to a problem situation as emotions encourage for acting by use of an immediate plan of action. The main thing is that emotional processes and states have their own special positive development in man [12]. Therein, it is widely believed that men and women differ in their emotional responding [14]. The positive development of emotional processes and states must be especially emphasized in as much as the classical conceptions of human emotions as "rudiments" coming from Darwin, consider their transformation in man as their involution, which generates a false ideal of education, leading to the requirement to "subordinate feelings to cold reason" [12]. Consequently, the relationship between human emotions and age has to be further analysed. Emotions are not only feelings, but also other elements, such as expressions in the face or the voice, physiological changes, and changes in action tendencies or action readiness [20]. Emotions fulfill the functions of internal signals, internal in the sense that they do not appear directly as psychic reflection of objective activity itself [12]. The special feature of emotions identified by Leont'ev [12] is that they reflect relationships between motives (needs) and success, or the possibility of success, of realizing the action of the subject that responds to particular motives. Therein, emotions do not reflect those relationships but reveal a direct sensory reflection of emotions, about experiencing [12]. In the present contribution, students' attitude is mediated via application of mobile social media in distance learning within higher education. It should be noted that in pedagogy experience includes knowledge, skills and attitude. Consequently, the terms experience and competence are used synonymously.
Further on, emotions are relevant to the social activity and not to individual actions or operations that realize it [12]. As a result emotions are not subordinated to activity but appear to be its result and the "mechanism" of its movement [12]. Hence, other participants within the environment of distance learning may influence students' attitude to mobile social media in distance learning within higher education.

For the cultural dimension of the process of application of mobile technologies in distance learning within higher education, it is important that the experience and expression of emotions depend on learned convictions or rules and, to the extent that cultures differ in the way they talk about and conceptualize emotions, how they are experienced and expressed will differ in different cultures as well [4]. Consequently, taking into consideration the discipline culture, as emotional practitioners, students can make the process of application of mobile technologies in distance learning within higher education exciting or dull [10]. Moreover, students' interactions can be crucial in developing students' academic self-concept and enhancing their motivation and achievement [11]. Thereby, on the one hand, emotion reflects the culture trait of a person [9], and, on the other hand, the emotions are social constructions [1]. Analysis of the interrelationship between attitude and emotions contributes to the identification of attitude's indicators and constructs presented in Table 2.

Table 2: Attitude’s indicators and constructs

\begin{tabular}{|c|c|c|}
\hline Criterion & Indicators & Constructs \\
\hline $\begin{array}{l}\text { Evaluative } \\
\text { judgement }\end{array}$ & $\begin{array}{c}\text { Verbal } \\
\text { expression }\end{array}$ & A word, sentence, etc \\
\cline { 2 - 3 } & $\begin{array}{c}\text { Non-verbal } \\
\text { expression }\end{array}$ & $\begin{array}{c}\text { Face expression, body } \\
\text { language, mimicry, etc }\end{array}$ \\
\cline { 2 - 3 } & $\begin{array}{c}\text { Cultural } \\
\text { expression }\end{array}$ & Cultural habits \\
\hline
\end{tabular}

Such constructs of verbal expression as a word or sentence may express a positive or negative meaning. For example, "excellent" is considered as a construct that demonstrates a positive attitude, "moderate" - neutral, and "bad" - negative. Regarding non-verbal expression of attitude, smiling face means positive attitude, a neutral voice tone neutral attitude, crossing one's arms - negative attitude. Such constructs of cultural expression as applauding demonstrates positive attitude, listening without a comment - neutral, and turning one's back to a colleague - negative.

In distance learning within higher education, students' attitude is mediated via application of mobile social media.

Mobile social media refers to the combination of mobile devices and social media as illustrated in Figure 4. 


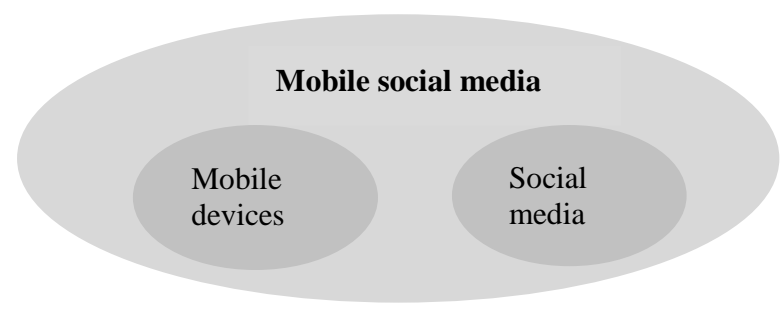

Figure 4: Elements of mobile social media

By mobile devices, smart phones, laptops, tablet personal computers, ultra compact computers, hybrid devices, etc. are meant. Mobile technologies are connected to the Internet via wireless access that ensures mobility in distance learning.

As higher education is centred on research, and research is a kind learning, social media in distance learning in higher education focuses on use of

- university e-Libraries,

- patent databases such as European Patent Office (EPO), US Patent and Trademark Office (PTO),

- bibliographic databases such as SciVerse Scopus (SCOPUS), Thomson Reuters, Education Resources Information Center (ERIC),

- research communities' networks such as www. researchgate.com, www.ResearcherID.com, etc.

University e-Libraries provide access to eResources such as electronic resources, i.e., online journals, indexes, databases, and books that is restricted by licenses with vendors to university's students, faculty, and staff. A particular university's students, faculty, and staff have off-campus access is only ensured to these licensed eResources.

Patent database enables users to search the full text of multiple international patent collections. Users can search published applications, granted patents and utility models mostly from 1985 to the present time. The data available includes full text patents, English machine translations and full document images. These collections are periodically updated to include additional years of coverage.

A bibliographic database is a database of bibliographic records, an organized digital collection of references to published literature, including journal and newspaper articles, conference proceedings, reports, government and legal publications, patents, books, etc. In contrast to library catalogue entries, a large proportion of the bibliographic records in bibliographic databases describe articles, conference papers, etc., rather than complete monographs, and they generally contain very rich subject descriptions in the form of keywords, subject classification terms, or abstracts [7]. A bibliographic database may be general in scope or cover a specific academic discipline. A significant number of bibliographic databases are still proprietary, available by licensing agreement from vendors, or directly from the indexing and abstracting services that create them [17]. Many bibliographic databases evolve into digital libraries, providing the full-text of the indexed contents.

Research community networks in the present contribution mean use of web-based tools to discover and use research and scholarly information about people and resources. Research community networks [2] include four technology components such as a controlled vocabulary (eg., the VIVO (literally 'inside the living') Ontology) for data interoperability, an architecture for data integration and sharing (Linked Open Data), applications for collaboration, funding, business intelligence, or administration and rich faculty profile data of publications, grants, classes, affiliations, interests, etc. Research community networks' tools facilitate the development of new collaborations and team science to address new or existing research challenges through the rapid discovery and recommendation of researchers, expertise, and resources [3, 6]. Research community networks' tools differ from search engines such as Google in that they access information in databases and other data not limited to web pages. They also differ from social networking systems such as LinkedIn or Facebook in that they represent a compendium of data ingested from authoritative and verifiable sources rather than predominantly individually asserted information, making research community networks' tools more reliable. Yet, research community networks' tools have sufficient flexibility to allow for profile editing. Research community networks' tools also provide resources to bolster human connector systems: they can make nonintuitive matches, they do not depend on serendipity, and they do not have a propensity to return only to previously identified collaborations/collaborators. Research community networks' tools also generally have associated analytical capabilities that enable evaluation of collaboration and cross-disciplinary research/scholarly activity, especially over time. Importantly, data harvested into robust research community networks' tools is accessible for broad repurposing, especially if available as linked open data (Resource Description Framework (RDF) triples). Thus, research community networks' tools enhance research support activities by providing data for customized, up-to-date web pages, curriculum vitae (CV) / biosketch generation, and data tables for grant proposals. Research community networks demonstrate such opportunities as [2] support to innovative team building approaches, provision of richer data for comparative institutional studies and potential for national networks of collaborative research.

Research community networks reveal the existence of such threats as [2] some desired data are private (eg., award amounts) or restricted (eg., the Family Educational Rights and Privacy Act of 1974 
(FERPA or the Buckley Amendment that is a United States federal law), negotiation between research and administrative efforts is required, and efforts threaten established networks of research influence.

A couple of educational models of distance learning exist in higher education:

- Distance learning means any learning system where teaching behaviors are separated from learning behaviors. The learner works alone, guided by study material arranged by the instructor in a location apart from students. Students have the opportunity to communicate with an instructor with the aid of a range of media (such as text, telephone, audio, video, computing and Internet technology, etc).

- Distance learning may be combined with various forms of face-to-face meetings.

- Remote access to learning materials, databases and libraries, electronic communication, computer-connected workgroups, archived lectures, and other features of distance learning increasingly are used in campus-based instruction. The terms “distance learning” and "e-learning' are used synonymously in the present contribution. Distance learning is identified as an element of blended learning as presented in Figure 5.

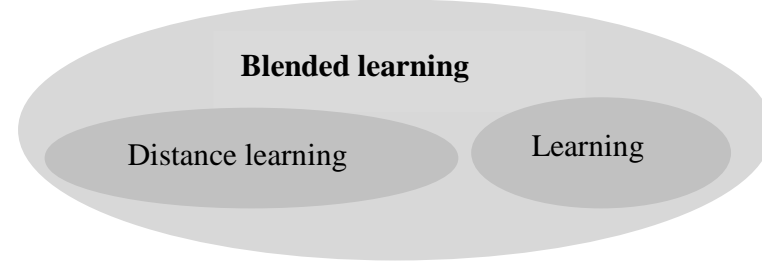

Figure 5: The relationship between

blended learning, distance learning and learning

Distance learning is defined as a purposefully organized or spontaneous process of students' improvement of his/her individual experience and, consequently, competence (knowledge, skills and attitudes) based on cognition via use of mobile social media. In the present research, the process of distance learning proceeds as a cycle. The cycle of the process of distance learning of three phases is proposed, namely, preparation in Phase 1, implementation in Phase 2 and analysis in Phase 3. Phase 1 Preparation is aimed at planning the implementation of distance learning, choosing forms of information compilation and using resources for the implementation of distance learning. Phase 2 Implementation is focused on analysis of an open problem situation and search for a solution. Phase 3 Analysis includes evaluation of the distance learning results and elaboration of further perspectives.

Distance learning being a part of blended learning is implemented as a phase in the blended educational process. The blended educational process proceeds as demonstrated in Figure 6 from blended teaching in Phase 1 through blended peerlearning in Phase 2 to blended learning in Phase 3.

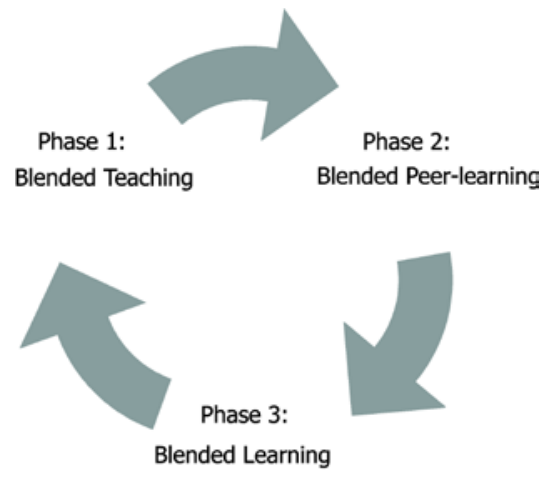

Figure 6: The phases of the blended educational process

Phase 1 Blended Teaching is aimed at a safe environment for all the students. In order to provide a safe environment, the essence of constructive social interaction and its organizational regulations are considered by both the educator and students. The present phase of the blended educational process is organized in a frontal way involving the students to participate.

- Educator makes previous experience rational.

The activity includes choice of forms and use of resources including mobile social media that motivates the students. The blended teaching process is under the educator's guidance.

- Peers do not participate in guidance of the blended educational process. This phase of the blended educational process is carried out qualitatively only with the help of the educator. Dependence on the educator is observed. The students study alongside but not together.

- Students create the system of the aim and objectives, search for a variety of information source including mobile social media and obtain techniques of information compiling including mobile social media. Students fulfil the present phase of the blended educational process qualitatively only with the educator's help. Dependence on the educator is observed, not dependent on peers.

Phase 2 Blended Peer-learning is designed for the students' analysis of an open academic problem situation and their search for a solution including mobile social media. The same materials can be prepared for all of the group students. But these materials are different whereas learning styles and opportunities are different. This phase of the blended educational process involves the students to act in peers.

- Educator functions as a resource and moderator. Educator delegates his/her duties to the students. 
- Peers regulate each other: it is typical for students to regulate each other. The students study together, study from others including and teach others including mobile social media. The present phase of the blended educational process is under peer's guidance. Forms and methods of the blended educational process are exchanged.

- The students fulfil the present phase of the blended educational process qualitatively with the peers' help. Partial independence is observed. The relevant activity is performed jointly with other students and with shared responsibility. It is typical for students to regulate each other.

Phase 3 Blended Learning emphasizes the students' self-regulation with use of assessment of the process and self-evaluation of the results.

- Educator functions as a consultant and an assistant. Educator delegates his/her duties to the students.

- Peers have consultative and advisory functions including mobile social media.

- Students' self-regulation is typical. The students learn independently including mobile social media. The students fulfil the present phase of the blended educational process including mobile social media qualitatively on their own, and their independence is observed. The participants' selfregulation on the basis of the process assessment and the result of self-evaluation is used. The relevant activity is performed with a high sense of responsibility. Self-regulation is typical, and a student does not depend on peers.

Description of the implementation of the phases of the blended educational process as well as the finding that other participants within the environment of distance learning may influence students' attitude to mobile social media in distance learning within higher education allow concluding that educators and peers influence students' attitude to mobile social media in distance learning within higher education.

\section{Empirical Study}

The present part of the contribution demonstrates the design of the empirical research, survey results, and findings of the comparative study.

The design of the present empirical research comprised the purpose and question, sample and methodology of the present empirical study.

The guiding question of the empirical study was as follows: is there a difference between educator's and peers' influence on students' attitude to mobile social media in distance learning? The purpose of the empirical study was to compare educator's and peers' influence on students' attitude to mobile social media in distance learning underpinning elaboration of a hypothesis.
As sample size has a two-fold role in research, namely sample size is inter-connected with statistical analysis of the data and generalization, the sample size was formed by the factors revealed in Table 3 .

Table 3: Factors that influence sample size in educational research

\begin{tabular}{|l|l|}
\hline \multicolumn{2}{|c|}{$\begin{array}{c}\text { Factors that influence sample size in educational } \\
\text { research }\end{array}$} \\
\hline External Perspective & \multicolumn{1}{|c|}{ Internal Perspective } \\
\hline Surroundings' and & Researcher factors: \\
resources' factors: & - aims of research, \\
- access to the sample & - aims of generalisation, \\
- resources: & - research methodologies, \\
- time, & - educational research \\
- personnel and its & paradigm, \\
competences and & - motivation, \\
experiences, & - interest, \\
- technical support, & - skills, and \\
- measurement procedures, & - experience \\
etc &
\end{tabular}

The present empirical study was carried out 2014. The sample was composed of 21 engineering students of Baltic Summer School Technical Informatics and Information Technology held at Riga Technical University, Riga, Latvia, July 21 - August 4, 2014. The sample involved six female students and 15 male students. The age of students ranged between 20 and 35. All 21 students had received Bachelor or Master Degree or were involved in $\mathrm{PhD}$ studies in different fields of computing. Working experience of the students was different, too. Although the students studied in the same group, the students represented different cultures, namely Ukraine, Uzbekistan, Azerbaijan, Estonia, Lithuania, Kazakhstan, Latvia, Germany, Egypt, Iran, Sweden, Vietnam and Nigeria. Therefore, the sample is multicultural as the respondents with different cultural backgrounds and diverse educational approaches were chosen. Students' different cultural and educational experience emphasized the significance of each student's contribution to the analysis of educator's and peers' influence on their attitude to mobile social media in distance learning of higher education. Thus, the groups' socio-cultural context (age, cultural and educational experience, mother tongue, etc.) is heterogeneous.

The interpretive paradigm was used in the empirical study. The interpretive paradigm aims to understand other cultures, from the inside through the use of ethnographic methods such as informal interviewing and participant observation, etc [19]. Interpretive research paradigm corresponds to the nature of humanistic pedagogy [13]. The interpretative paradigm allows creating an environment for the development of any individual and helps them to develop their potential [13]. The 
core of this paradigm is human experience, people's mutual everyday interaction that tends to understand the subjectivity of human experience [13]. The paradigm is aimed at understanding people's activity, how a certain activity is exposed in a certain environment, time, conditions, i.e., how it is exposed in a certain socio-cultural context [13]. Thus, the interpretative paradigm is oriented towards one's conscious activity, and it is future-oriented [13]. Interpretive paradigm is characterized by the researcher's practical interest in the research question. Researcher is the interpreter.

The exploratory type of the comparative study has been applied. The exploratory type of the comparative study aims to generate new hypotheses and questions. The exploratory methodology proceeds

- from Phase 1 Exploration aimed at data collection

- through Phase 2 Analysis focused on data processing, analysis and data interpretation

- $\quad$ to Phase 3 Hypothesis Development oriented to analysis of results of the empirical study and elaboration of conclusions and hypotheses for further research.

In order to analyse the students' feedback regarding educator's and peers' influence on their attitude to mobile social media in distance learning within higher education, the informal structured interviews were based on the following questions:

- Question 1: Does your educator develop your use of mobile social media in distance learning?

- Question 2: Do your peers enrich your use of mobile social media in distance learning?

Only verbal expression of engineering students' attitude to mobile social media in distance learning was taken into consideration. The evaluation scale of five levels for the question was given, namely, strongly disagree “ 1 ”, disagree " 2 ", neither disagree nor agree „3“, agree “ 4 ”, and strongly agree “5”. The evaluation scale was transformed into the level system as illustrated in Table 4.

The results of Question 1 (Educator' influence on students' attitude to mobile social media in distance learning) of the questionnaire used in the survey show that

- two students' - one male and one female evaluation of their educator's influence on their mobile social media in distance learning refers to the very low level,

- two students' - two male - evaluation of their educator's influence on their mobile social media in distance learning refers to the low level,

- one students' - one female - evaluation of his/her educator's influence on his/her mobile social media in distance learning refers to the average level,

- six students' - five male and one female evaluation of his/her educator's influence on his/her mobile social media in distance learning refers to the optimal level,

- 10 students' - seven male and three female evaluation of his/her educator's influence on his/her mobile social media in distance learning refers to the high level.

The results of the question (Educator' influence on students' attitude to mobile social media in distance learning) show that the majority of engineering students' evaluate their educator's influence on their attitude to mobile social media in distance learning to be of the high level.

Table 4. Indicators and levels of educator's and peers' influence on students' attitude to mobile social media in distance learning

\begin{tabular}{|c|c|c|c|c|c|}
\hline \multirow{4}{*}{$\begin{array}{l}\text { Indi- } \\
\text { cator }\end{array}$} & \multicolumn{5}{|c|}{ Levels } \\
\hline & $\begin{array}{c}\text { Level } \\
1 \\
\end{array}$ & $\begin{array}{l}\text { Leve } \\
12\end{array}$ & Level 3 & $\begin{array}{c}\text { Leve } \\
14\end{array}$ & $\begin{array}{c}\text { Level } \\
5\end{array}$ \\
\hline & $\begin{array}{l}\text { very } \\
\text { low }\end{array}$ & low & $\begin{array}{c}\text { averag } \\
e\end{array}$ & $\begin{array}{l}\text { opti } \\
\text { mal }\end{array}$ & high \\
\hline & 1 & 2 & 3 & 4 & 5 \\
\hline \multirow[t]{2}{*}{$\begin{array}{l}\text { Verbal } \\
\text { expres } \\
\text {-sion }\end{array}$} & $\begin{array}{l}\text { Strong } \\
\text {-ly dis- } \\
\text { agree }\end{array}$ & $\begin{array}{c}\text { Dis- } \\
\text { agree }\end{array}$ & $\begin{array}{c}\text { Neither } \\
\text { disagree } \\
\text { nor } \\
\text { agree }\end{array}$ & Agree & $\begin{array}{c}\text { Strong } \\
\text {-ly } \\
\text { agree }\end{array}$ \\
\hline & $\begin{array}{l}\text { Very } \\
\text { negati } \\
\text {-ve }\end{array}$ & $\begin{array}{c}\text { Nega- } \\
\text { tive }\end{array}$ & $\begin{array}{c}\text { Neither } \\
\text { negative } \\
\text { nor } \\
\text { positive }\end{array}$ & $\begin{array}{c}\text { Positi } \\
\text {-ve }\end{array}$ & $\begin{array}{c}\text { Very } \\
\text { positi- } \\
\text { ve }\end{array}$ \\
\hline
\end{tabular}

The results of Question 2 (Peers' influence on students' attitude to mobile social media in distance learning) demonstrate that

- three students' - two male and one female evaluation of their peers' influence on their mobile social media in distance learning refers to the very low level,

- one students' - one male - evaluation of his/her peers' influence on his/her mobile social media in distance learning refers to the low level,

- five students' - four male and one female evaluation of their peers' influence on their mobile social media in distance learning refers to the average level,

- seven students' - five male and two female evaluation of their peers' influence on their mobile social media in distance learning refers to the optimal level,

- four students' - two male and two female evaluation of their peers' influence on their mobile social media in distance learning refers to the high level.

Table 5. Frequency of the students’ answers 


\begin{tabular}{|c|c|c|c|c|c|c|}
\hline Indicator & Levels & $\begin{array}{c}\text { Number of } \\
\text { answers }\end{array}$ & Gender & $\begin{array}{c}\text { Number of } \\
\text { answers by gender }\end{array}$ & Percentage & $\begin{array}{c}\text { Percentage by } \\
\text { gender }\end{array}$ \\
\hline \multirow{10}{*}{$\begin{array}{l}\text { Educator } \\
\text { 's influence } \\
\text { on students' } \\
\text { attitude to } \\
\text { mobile social } \\
\text { media in } \\
\text { distance } \\
\text { learning }\end{array}$} & \multirow{2}{*}{ very low } & \multirow[t]{2}{*}{ 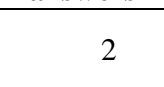 } & male & 1 & \multirow{2}{*}{$9.52 \%$} & $4.76 \%$ \\
\hline & & & female & 1 & & $4.76 \%$ \\
\hline & \multirow{2}{*}{ low } & \multirow{2}{*}{2} & male & 2 & \multirow{2}{*}{$9.52 \%$} & $9.52 \%$ \\
\hline & & & female & 0 & & $0.00 \%$ \\
\hline & \multirow{2}{*}{ average } & \multirow{2}{*}{1} & male & 0 & \multirow{2}{*}{$4.76 \%$} & $0.00 \%$ \\
\hline & & & female & 1 & & $4.76 \%$ \\
\hline & \multirow{2}{*}{ optimal } & \multirow{2}{*}{6} & male & 5 & \multirow{2}{*}{$28.57 \%$} & $23.80 \%$ \\
\hline & & & female & 1 & & $4.76 \%$ \\
\hline & \multirow{2}{*}{ high } & \multirow{2}{*}{10} & male & 7 & \multirow{2}{*}{$47.61 \%$} & $33.33 \%$ \\
\hline & & & female & 3 & & $0.00 \%$ \\
\hline \multirow{10}{*}{$\begin{array}{c}\text { Peers' } \\
\text { influence on } \\
\text { students' } \\
\text { attitude to } \\
\text { mobile social } \\
\text { media in } \\
\text { distance } \\
\text { learning }\end{array}$} & \multirow{2}{*}{ very low } & \multirow{2}{*}{3} & male & 2 & \multirow{2}{*}{$14.28 \%$} & $9.52 \%$ \\
\hline & & & female & 1 & & $4.76 \%$ \\
\hline & \multirow{2}{*}{ low } & \multirow{2}{*}{1} & male & 1 & \multirow{2}{*}{$4.76 \%$} & $4.76 \%$ \\
\hline & & & female & 0 & & $0.00 \%$ \\
\hline & \multirow{2}{*}{ average } & \multirow{2}{*}{5} & male & 4 & \multirow{2}{*}{$23.80 \%$} & $23.07 \%$ \\
\hline & & & female & 1 & & $4.76 \%$ \\
\hline & \multirow{2}{*}{ optimal } & \multirow{2}{*}{7} & male & 5 & \multirow{2}{*}{$33.33 \%$} & $23.80 \%$ \\
\hline & & & female & 2 & & $9.52 \%$ \\
\hline & \multirow{2}{*}{ high } & \multirow{2}{*}{4} & male & 2 & \multirow{2}{*}{$19.04 \%$} & $9.52 \%$ \\
\hline & & & female & 2 & & $9.52 \%$ \\
\hline
\end{tabular}

Table 6. Frequency of the students' answers

The results of the question (Peers' influence on

\begin{tabular}{|c|c|c|c|c|c|c|}
\hline Indicator & Levels & $\begin{array}{c}\text { Number of } \\
\text { answers }\end{array}$ & Gender & $\begin{array}{c}\text { Number of } \\
\text { answers by gender }\end{array}$ & Mean & $\begin{array}{c}\text { Mean by } \\
\text { gender }\end{array}$ \\
\hline \multirow{10}{*}{$\begin{array}{l}\text { Educator } \\
\text { 's influence } \\
\text { on students' } \\
\text { attitude to } \\
\text { mobile social } \\
\text { media in } \\
\text { distance } \\
\text { learning }\end{array}$} & \multirow{2}{*}{ very low } & \multirow{2}{*}{2} & male & 1 & \multirow{10}{*}{3.95} & \multirow{2}{*}{ Male } \\
\hline & & & female & 1 & & \\
\hline & \multirow{2}{*}{ low } & \multirow{2}{*}{2} & male & 2 & & \multirow{3}{*}{3.86} \\
\hline & & & female & 0 & & \\
\hline & \multirow{2}{*}{ average } & \multirow{2}{*}{1} & male & 0 & & \\
\hline & & & female & 1 & & \multirow{3}{*}{ Female } \\
\hline & \multirow{2}{*}{ optimal } & \multirow{2}{*}{6} & male & 5 & & \\
\hline & & & female & 1 & & \\
\hline & \multirow{2}{*}{ high } & \multirow{2}{*}{10} & male & 7 & & \multirow[t]{2}{*}{4.0} \\
\hline & & & female & 3 & & \\
\hline \multirow{10}{*}{$\begin{array}{c}\text { Peers' } \\
\text { influence on } \\
\text { students' } \\
\text { attitude to } \\
\text { mobile social } \\
\text { media in } \\
\text { distance } \\
\text { learning }\end{array}$} & \multirow{2}{*}{ very low } & \multirow{2}{*}{3} & male & 2 & \multirow{10}{*}{3.23} & \multirow{3}{*}{ Male } \\
\hline & & & female & 1 & & \\
\hline & \multirow{2}{*}{ low } & \multirow{2}{*}{1} & male & 1 & & \\
\hline & & & female & 0 & & \multirow[t]{2}{*}{3.06} \\
\hline & \multirow{2}{*}{ average } & \multirow{2}{*}{5} & male & 4 & & \\
\hline & & & female & 1 & & \multirow{5}{*}{ Female } \\
\hline & \multirow{2}{*}{ optimal } & \multirow{2}{*}{7} & male & 5 & & \\
\hline & & & female & 2 & & \\
\hline & \multirow{2}{*}{ high } & \multirow{2}{*}{4} & male & 2 & & \\
\hline & & & female & 2 & & \\
\hline
\end{tabular}

students' attitude to mobile social media in distance software. Frequencies of the engineering students' learning) show that the majority of engineering students' evaluate their peers' influence on their attitude to mobile social media in distance learning to be of the optimal level. answers were determined in order to reveal educator' and peers' influence on students' attitude to mobile social media in distance learning as shown in Table 5.

The frequencies of engineering students' answers to the questions (educator's and peers' influence on 
students' attitude to mobile social media in distance learning) show that the majority of engineering students' evaluate educator's and peers' influence on their attitude to mobile social media in distance learning to be of the high level (47.61\%) and the optimal level (33.33\%) respectively.

Further on, the mean results determine the average level of educator's and peers' influence on the engineering students' attitude to mobile social media in distance learning (3.95 and 3.23 respectively) as shown in Table 6.

The findings of the empirical study allow concluding that educator's and peers' influence on the engineering students' attitude to mobile social media in distance learning (3.95 and 3.23 respectively). As well as the female students demonstrated a higher level of educator's and peers' influence on their attitude to mobile social media in distance learning (4.0 and 3.83 respectively) in comparison to the male students (3.86 and 3.06 respectively). The comparison of educator's and peers' influence on their attitude to mobile social media in distance learning reveals that educator's and peers' influence on their attitude to mobile social media in distance learning is of the same level, namely the average level. The summarizing content analysis of the data reveals that engineering students' evaluation of their educator's and peers' influence on their attitude to mobile social media in distance learning within higher education is homogeneous.

\section{Conclusions}

The theoretical findings allow determining the key participants of the blended educational process, namely educators and peers, who influence students' attitude to mobile social media in distance learning within higher education.

The findings of the present empirical study allow drawing conclusions that students' attitude to mobile social media in distance learning within higher education is influenced by educators and peers. Further on, educator's and peers' influence on students' attitude to mobile social media in distance learning within higher education is homogeneous. Another conclusion is drawn that female students are more influenced by educators and peers in comparison to the male students as men and women differ in their emotional responding [14].

Both educator's and peers' homogeneous influence on students' attitude to mobile social media in distance learning within higher education is considered as a favourable opportunity for the increase of the level of students' knowledge and skills as well as competence in use of mobile social media in distance learning, in general.

The following hypothesis has been formulated: students' positive attitude to mobile social media in distance learning within higher education promotes the increase of the level of students' knowledge and skills as well as competence in general if

- a favourable blended educational environment is organized within higher education,

- the blended educational process is focused on use of mobile social media in distance learning,

- blended educational process proceeds from blended teaching through blended peer-learning to blended learning, thereby equally distributing educator's and peers' impact on students' attitude to mobile social media in distance learning within the blended educational process.

The present research has limitations. The interconnections between students' attitude, emotions, mobile social media, distance learning, blended learning and blended educational process have been set. Another limitation is the empirical study conducted by involving only engineering students. A limitation is the empirical study carried out in one higher education institution. Therein, the results of the study cannot be representative for the whole area. Nevertheless, the results of the research - the key participants of the blended educational process, namely educators and peers, who influence students' attitude to mobile social media in distance learning within higher education and the design of the empirical study - may be used as a basis of analysis of impact on the students' attitude to to mobile social media in distance learning within higher education in other institutions. If the results of other institutions had been available for analysis, different results could have been attained. There is a possibility to continue the study.

Other participants who might influence students' attitude to mobile social media in distance learning within higher education have to be identified. Impact of other participants on students' attitude to mobile social media in distance learning within higher education is to be analysed. The search for relevant methods for evaluation of impact on students' attitude to mobile social media in distance learning is proposed. Further empirical studies could be focused on the analysis of other indicators of attitude, namely, non-verbal and cultural expression. A comparative research of other countries could be carried out, too.

\section{References}

[1] J.R. Averill, “A constructivist view of emotion”, In Emotion: Theory, research and experience, edited by R. Plutchik, H. Kellerman, H., New York: Academic Press, 1980, pp. 305-339.

[2] W. Barnett, J. Jardines, Technology now: Research Networking. The Clinical and Translational Science Award (CTSA) Research Networking Affinity Group, 2012 
[3] J. Carey, "Faculty of 1000 and VIVO: Invisible colleges and team science", Issues in Science and Technology Librarianship Number 65 Spring, 2011.

[4] R.R. Cornelius, The science of emotion: Research and tradition in the psychology of emotion. New York: Prentice Hall, 1996.

[5] S. Crites, L.R. Fabrigar, R.E. Petty, R. E. "Measuring the affective and cognitive properties of attitudes: Conceptual and methodological issues". Personality and Social Psychology Bulletin (20) 1994, 619-634.

[6] M. Fazel-Zarandi, H.J. Devlin Y. Huang, N. Contractor, "Expert recommendation based on social drivers, social network analysis, and semantic data representation". 2nd International Workshop on Information Heterogeneity and Fusion in Recommender Systems, ACM, Chicago, IL, 2011, pp. 41-48.

[7] J. Feather, P. Sturges, International Encyclopedia of Information and Library Science (Second ed.). London: Routledge. p. 127, 2003.

[8] J.B. Ferreira, A.Z. Klein, A. Freitas, E. Schlemmer, "Mobile Learning: Definition, Uses and Challenges", In Laura A. Wankel, Patrick Blessinger (ed.) Increasing Student Engagement and Retention Using Mobile Applications: Smartphones, Skype and Texting Technologies (Cutting-edge Technologies in Higher Education, Volume 6), Emerald Group Publishing Limited, 2013, pp. 47-82.

[9] R. Harré, The social construction of emotion. New York: Basil Blackwell, 1986.

[10] A. Hargreaves, The emotional practice of teaching. Teaching and Teacher Education 14, 1998, pp. 835-854.

[11] M. Komarraju, S. Musulkin, G. Bhattacharya, Role of Student-Faculty Interactions in Developing College Students' Academic Self-Concept, Motivation, and Achievement. Journal of College Student Development, 2010, pp. 332-342.

[12] A. N. Leont'ev, Activity, Consciousness, and Personality. Prentice-Hall, 1978.

[13] I. Lūka, Development of Students' ESP Competence and Educator's Professional Activity in Tertiary Level Tourism Studies. Proceedings of ATEE Spring University Conference Teacher of the 21st Century: Quality Education for Quality Teaching, Riga, Latvia: University of Latvia, 2008, pp. 689-697.

[14] K. McRae, K.N. Ochsner, I.B. Mauss, J.J.D. Gabrieli J.J. Gross, Gender Differences in Emotion Regulation: An fMRI Study of Cognitive Reappraisal. Group Processes Intergroup Relations 2008; 11; 143-162.

[15] S.A. Palmer, D.M. Holt, "Students' perceptions of the value of the elements of an online learning environment: Looking back in moving forward", Interactive Learning Environments Volume 18, Issue 2, 2010, pp. 135-151.
[16] S. Parise, E. Crosina, "How a Mobile Social Media Game Can Enhance the Educational Experience", MERLOT Journal of Online Learning and Teaching Vol. 8, No. 3, September 2012.

[17] J.M. Reitz, "Bibliographic database". Dictionary for Library and Information Science. Westport, Connecticut: Libraries Unlimited. 2004, p. 70.

[18] A. Špona, Z. Čehlova, Pētniecība pedagoǵijā. Rīgā: RaKa. (in Latvian), 2004.

[19] P.C. Taylor, M.N.D. Medina, Educational Research Paradigms: From Positivism to Multiparadigmatic. The Journal of Meaning-Centered Education. 1, Article 2, 2013.

[20] J.P. De Vierville, Emotion. Electronic library of Waikato University, 1999. 